\title{
Espinelização in-situ e seu efeito na resistência ao choque térmico de concretos refratários
}

\author{
(In-situ spinelization and thermal shock performance \\ of refractory castables)
}

\author{
G. B. Cintra ${ }^{1}$, M. A. L. Braulio ${ }^{1}$, M. A. M. Brito ${ }^{2}$, L. R. M. Bittencourt ${ }^{2}$, V. C. Pandolfelli ${ }^{1}$ \\ ${ }^{I}$ Grupo de Engenharia de Microestrutura de Materiais - GEMM \\ Departamento de Engenharia de Materiais, Universidade Federal de S. Carlos \\ Rod. Washington Luiz, km 235, C.P. 676, S. Carlos, SP 13565-905 \\ ${ }^{2}$ Magnesita S.A., Centro de Pesquisas e Desenvolvimento - CPqD \\ Praça Louis Ensch 240, Contagem, MG \\ vicpando@power.ufscar.br
}

\begin{abstract}
Resumo
O desempenho de uma panela siderúrgica está atrelado ao seu revestimento refratário. Devido à elevada agressividade da escória presente no aço fundido, é fundamental a utilização de revestimentos de alta resistência à corrosão. Concretos refratários aluminosos contendo espinélio são amplamente utilizados em tal aplicação por apresentarem esta característica. Neste contexto, destacamse os concretos refratários do sistema alumina-magnésia, uma vez que a formação de espinélio in-situ é benéfica em termos termodinâmicos e microestruturais. Considerando-se que as panelas sofrem constantemente variações bruscas de temperatura, devido à ciclagem térmica, a análise da resistência ao choque térmico é um parâmetro fundamental para a correta seleção do revestimento refratário. Sendo assim, o objetivo deste trabalho é caracterizar o efeito das variações dos componentes da matriz dos concretos $\mathrm{Al}_{2} \mathrm{O}_{3}-\mathrm{MgO}$ e suas conseqüências nos danos causados por choque térmico. Os resultados mostraram que os concretos com espinelização in-situ apresentaram desempenho inferior àqueles com adição de espinélio pré-formado em ambientes sem constrição. Adicionalmente, a presença de microssílica aumentou o dano sofrido pelos concretos. Porém, deve-se considerar que o ensaio de caracterização foi realizado em temperaturas inferiores às de transição vítrea, podendo influenciar no resultado. A associação destes conhecimentos possibilita encontrar a melhor solução termomecânica associada a uma elevada resistência à corrosão química, resultando em maior vida útil e superior desempenho das panelas siderúrgicas.

Palavras-chave: concreto refratário, espinélio, choque térmico.
\end{abstract}

\begin{abstract}
The steel ladle working life is directly related with the refractory lining performance. Considering the great corrosion promoted by basic slags in the secondary steelmaking industry, the use of a high quality material is essential. The corrosion resistance is attained by the use of alumina-magnesia refractory castables, as the in-situ spinel formation leads to a better chemical performance. The steel ladles are also subjected to abrupt temperature changes, due to heating and cooling cycles. Therefore, the thermal shock evaluation is of utmost importance to a proper material selection. The objective of this paper is the analysis of the matrix components and its consequences on the thermal shock damage in order to attain the most suitable thermo mechanical solution coupled with a high corrosion resistance, resulting the increase of the life expectancy of a steel ladle. The results presented show that alumina-spinel castables had better performance than alumina-magnesia castables when there is no constraining. The presence of microssilica increased the thermal shock damage, and this may be related to the testing temperature range.
\end{abstract}

Keywords: refractory castable, spinel, thermal shock.

\section{INTRODUÇÃO}

Os revestimentos refratários das panelas de siderurgia estão expostos ao ambiente severo do processo de refinaria secundária, envolvendo elevadas temperaturas, escórias agressivas e elevados tempos de residência [1, 2]. Neste contexto, estão inseridos os concretos aluminosos contendo espinélio. A incorporação de espinélio em concretos de alta alumina auxilia na diminuição do desgaste no revestimento, por meio do aumento da resistência à corrosão de tais materiais [3].

O espinélio é uma fase cristalina formada pela reação entre a alumina e a magnésia, em temperaturas entre 1100 ${ }^{\circ} \mathrm{C}$ e $1400{ }^{\circ} \mathrm{C}$, possuindo excelentes propriedades refratárias, tais como alta resistência mecânica, elevada resistência à corrosão e à erosão, alta refratariedade e estabilidade química. 
A incorporação do espinélio em concretos aluminosos pode ser realizada de duas formas distintas: 1) Adição de espinélio pré-formado como matéria-prima durante a mistura do material; 2) Formação de espinélio in-situ por meio da adição de magnésia e reação em temperaturas elevadas com a alumina reativa presente na matriz do concreto.

As principais vantagens do uso de espinélios pré-formados se relacionam à presença desta fase em temperaturas inferior as de sua obtenção e com a ausência de expansão decorrente da sua formação in-situ. No entanto, o processo de préespinelização apresenta um consumo considerável de energia, o que resulta em elevado custo, além de seu desempenho termomecânico não ser tão eficiente quanto aquele gerado in-situ. Na espinelização in-situ, as dificuldades encontradas se referem justamente aos problemas de expansão, sejam eles decorrentes da hidratação da magnésia ou mesmo da reação de espinelização. A vantagem é a geração de um espinélio finamente disperso por toda a matriz do concreto aumentando a resistência à penetração de escórias. Adicionalmente, acredita-se que a expansão proveniente da formação de espinélio propicia a tenacificação e densificação do material, melhorando o desempenho do material.

Os concretos espinelizados devem estar aptos a suportar as severas solicitações termomecânicas de uso, dentre as quais se destacam o elevado gradiente térmico, caracterizado pela diferença de temperatura entre o interior da panela e a região externa, e o choque térmico, relacionado com a ciclagem térmica [4]. A degradação causada pelo choque térmico pode comprometer o bom desempenho obtido pela incorporação do espinélio, gerando trincas que aumentam a penetração do metal e diminuem a vida útil do revestimento. Estudos mostram que, uma vez atendidos os requisitos de resistência ao ataque químico e resistência à penetração do metal, a resistência ao dano por choque térmico se torna a propriedade de maior relevância na determinação da vida útil do revestimento [5].

Desta forma, o objetivo deste trabalho é avaliar a influência das variações microestruturais dos concretos aluminosos contendo espinélio sobre a resistência ao dano por choque térmico. Foram analisados os efeitos das diferentes formas de incorporação de espinélio no concreto e a influência da presença de microssílica e sua conseqüência na resistência ao choque térmico. $\mathrm{O}$ dano por choque térmico foi avaliado por meio da medida da variação de módulo elástico e da resistência mecânica, em função de ciclos de choque térmico.

\section{Choque térmico em concretos espinelizados}

O choque térmico consiste na geração de tensões termomecânicas no material, a partir da variação brusca de temperatura. Quando as tensões geradas são maiores que a tensão de ruptura do material ocorre a nucleação e propagação de trincas, danificando a estrutura do material [6]. Os materiais refratários são constantemente submetidos a situações de choque térmico durante as aplicações. As variações na temperatura de uso são muito superiores à diferença de temperatura mínima necessária para a nucleação e propagação de trinca (aproximadamente $70{ }^{\circ} \mathrm{C}$ ), o que implica que a formação de trincas em refratários geradas por choque térmico é praticamente inevitável [7].

Para aumentar a resistência ao dano por choque térmico em refratários é necessário criar mecanismos que dissipem a energia de propagação da trinca (mecanismos de tenacificação) impedindo que ela se propague de maneira catastrófica e danifique estruturalmente o revestimento, comprometendo a sua funcionalidade. Os mecanismos de tenacificação presentes na microestrutura do concreto estão diretamente relacionados com as matérias-primas utilizadas. Com isso, o entendimento do efeito das matérias-primas sobre a microestrutura é fundamental na determinação da resistência ao choque térmico apresentada pelo refratário.

Dentre os principais mecanismos utilizados em refratários para dificultar a propagação de trincas (aumentando a resistência ao choque térmico) encontram-se a adição de agregados, a formação de microtrincas, o aumento da porosidade e a formação de fases com formato de agulhas (whiskers). Outro fator que pode contribuir no aumento da resistência ao choque térmico em refratários é a aplicação de concretos com caráter expansivo em ambientes constritos. A constrição impede que o concreto expanda livremente, gerando um estado de compressão no material, reduzindo a tensão termomecânica gerada pelo choque térmico, além de comprimir a ponta da trinca, dificultando a sua propagação.

A principal variação microestrutural causada pelas diferentes formas de incorporação do espinélio está associada ao caráter expansivo da reação de formação do espinélio in-situ. Os concretos do sistema aluminamagnésia (espinelização in-situ) possuem maior expansão volumétrica que os concretos do sistema alumina-espinélio (adição de espinélio pré-formado). Esta característica pode ser benéfica no aumento da resistência ao choque térmico dos revestimentos usados nas panelas de refino do aço por

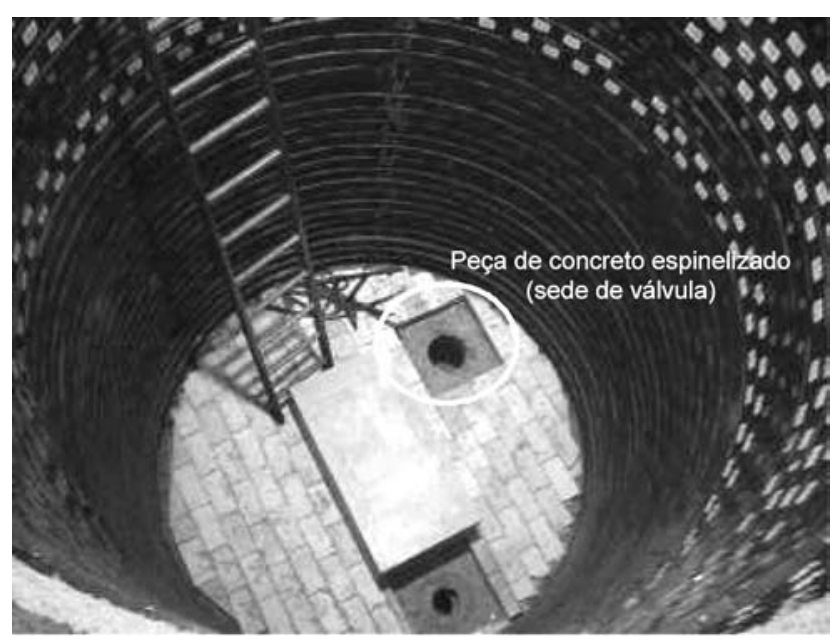

Figura 1: Restrição de espaço do concreto espinelizado em uma panela siderúrgica.

[Figure 1: Spinel castable under constraining in a steel ladle.] 
meio da tenacificação por constrição. As panelas possuem pouco espaço para acomodação dos concretos com expansão volumétrica, gerando um estado de compressão que tenacifica o material (Fig. 1).

A formação de espinélio in-situ pode tensionar a estrutura do concreto, e com isso, abrir trincas e aumentar a quantidade de poros quando esta reação ocorre em ambientes sem constrição. Dessa forma, os concretos do sistema aluminamagnésia possuem uma maior quantidade de microtrincas e poros presentes que os concretos do sistema aluminaespinélio, e como já foi visto, tanto as microtrincas quanto os poros são bons mecanismos de dissipação de energia de propagação de trinca, aumentando a resistência ao dano por choque térmico do material. No entanto, éimportante ressaltar que o microtrincamento em excesso pode gerar coalescência de trincas e reduzir a resistência ao choque térmico, além de afetar outras propriedades, como a permeabilidade.

Outra fase formada in-situ de grande relevância para a resistência ao choque térmico nos concretos espinelizados é o $\mathrm{CA}_{6}$, obtido em temperaturas superiores a $1400^{\circ} \mathrm{C}$, devido a reação do $\mathrm{CaO}$, advindo do cimento, com a alumina $\left(\mathrm{Al}_{2} \mathrm{O}_{3}\right)$. Esta reação também apresenta caráter expansivo, o que
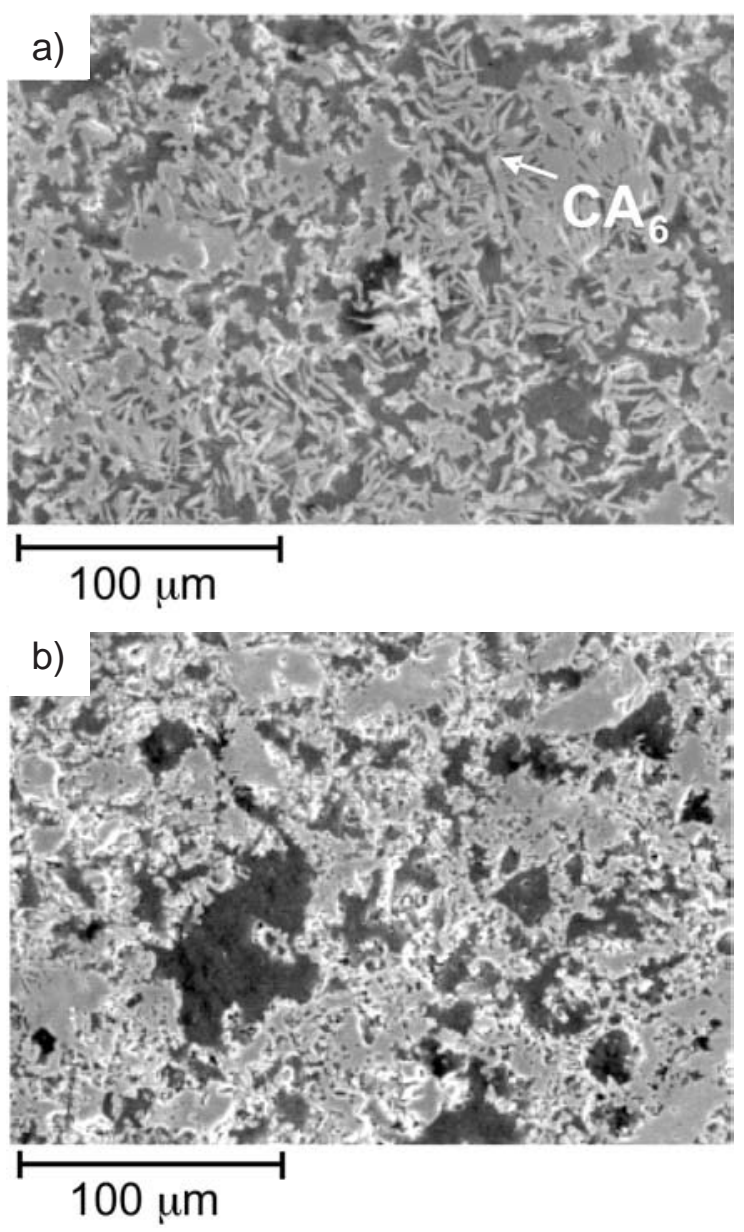

Figura 2: Efeito da adição de microssílica na formação do $\mathrm{CA}_{6}$ : a) com microssílica; b) sem microssílica [8].

[Figure 2: The effect of microssilica addition on the $\mathrm{CA}_{6}$ formation: a) with and b) without microssílica [8].] contribui para a geração de microtrincas. Adicionalmente, o $\mathrm{CA}_{6}$ possui morfologia acicular, auxiliando no aumento da resistência ao choque térmico.

A presença de microssílica em concretos espinelizados afeta consideravelmente a microestrutura dos concretos. Esta matéria-prima é adicionada para facilitar o processamento e acomodar as tensões de expansão decorrentes da formação de fases expansivas, como o espinélio e o $\mathrm{CA}_{6}$, por meio da formação de fase líquida em altas temperaturas. Além disso, esta fase liquida acelera a reação de formação do espinélio e do $\mathrm{CA}_{6}$, conforme indicado na Fig. 2. Neste caso, o concreto contendo microssílica apresenta formação mais intensa de $\mathrm{CA}_{6}$ que o concreto sem microssílica [8]. Com relação à resistência ao choque térmico em altas temperaturas a microssílica pode ser favorável uma vez que a presença de fase liquida ajuda a acomodar as tensões termomecânicas geradas, diminuindo a severidade do choque térmico, e com isso, reduzindo o desgaste. Além disso, aumenta a quantidade de $\mathrm{CA}_{6}$ na matriz, o número de microtrincas e de poros formados. Por outro lado, em temperaturas abaixo da de transição vítrea, a fase gerada pela presença de microssílica pode contribuir para a diminuição da resistência à propagação de trinca.

\section{MATERIAIS E MÉTODOS}

\section{Materiais}

Aluminas tabulares $\left(\mathrm{d}_{\max } \leq 6 \mathrm{~mm}\right)$ foram utilizadas como agregados dos concretos preparados (Almatis-EUA). A matriz dos concretos foi projetada com o uso de sínter de magnésia $\left(\mathrm{d}_{\max } \leq 45 \mathrm{~mm}\right.$ e $95 \%$ de $\mathrm{MgO}$; Magnesita S.A.Brasil), alumina reativa CL370 (Almatis-EUA) e microssílica 971 U (Elkem Materials - Noruega) para os concretos espinelizados in-situ. Já para os concretos pré-espinelizados foram selecionados espinélios estequiométricos em distintas granulometrias (AR78 da Almatis-EUA). Ambos os sistemas foram projetados para obtenção de um total de 21\%-p de espinélio. O ligante escolhido foi o cimento de aluminato de cálcio Secar 71 (Kerneos - França). Como dispersante foi usado um policarboxilato da Bayer (Alemanha).

Formulações com coeficientes de empacotamento 0,26 foram projetadas pelo modelo de Alfred por meio de um software desenvolvido em parceria entre o grupo de pesquisa GEMM/DEMa/UFSCar e a Alcoa Alumínio S.A.. Os concretos foram elaborados com teores de água que promovam uma fluidez mínima inicial sobre vibração de $80 \%$, garantindo moldagem adequada.

Os concretos foram moldados na forma de barras de secção retangular com dimensões aproximadas $150 \mathrm{~mm} \mathrm{x}$ $25 \mathrm{~mm} \times 25 \mathrm{~mm}$, curados em ambiente saturado por $24 \mathrm{~h}$, calcinados a $600^{\circ} \mathrm{C}$ e queimados por $5 \mathrm{~h}$ de patamar em três temperaturas distintas: $1150{ }^{\circ} \mathrm{C}, 1300{ }^{\circ} \mathrm{C}$ e $1500{ }^{\circ} \mathrm{C}$.

Os experimentos utilizados para caracterizar o dano por choque térmico nestes concretos foram: porosidade aparente, variação linear dimensional (VLD), ciclos de choque térmico, resistência mecânica e módulo elástico. 


\section{Medida das propriedades físicas}

A porosidade aparente foi medida utilizando-se o método de Arquimedes, onde os corpos de prova são imersos em querosene em ambiente de vácuo durante uma hora. A porosidade aparente foi calculada a partir dos valores de peso úmido, peso imerso e peso a seco, por meio da seguinte equação:

$$
\mathrm{PA}=\frac{\mathrm{P}_{\mathrm{u}}-\mathrm{P}_{\mathrm{s}}}{\mathrm{P}_{\mathrm{u}}-\mathrm{P}_{\mathrm{i}}} \cdot 100
$$

A medida da variação linear dimensional (VLD) residual do material foi efetuada em amostras na forma de barras (25 mm x 25 mm x $150 \mathrm{~mm}$ ). O cálculo de VLD é realizado por meio da medida do comprimento inicial da barra, antes da sinterização $\left(L_{\mathrm{i}}\right)$ e do comprimento final da amostra após sinterização $\left(\mathrm{L}_{\mathrm{f}}\right)$ :

$$
\mathrm{VLD}=\frac{\mathrm{L}_{\mathrm{f}}-\mathrm{L}_{\mathrm{i}}}{\mathrm{L}_{\mathrm{i}}} \cdot 100
$$

A medida de VLD é um indicativo da expansão residual do concreto após sinterização, podendo ser associada com algumas das fases formadas em altas temperaturas.

Ensaio de choque térmico e medida das propriedades mecânicas

Os ensaios de caracterização do dano por choque térmico realizados em laboratório seguem duas tendências: ciclo único e ciclos múltiplos. No primeiro caso, as amostras são submetidas a diferentes intervalos de temperatura e posteriormente, avalia-se a variação causada na resistência mecânica. No segundo caso, a diferença de temperatura é mantida fixa, e o choque térmico é repetido de maneira cíclica, medindo-se a variação da resistência mecânica em função do numero de ciclos [7, 9]. Este segundo método é mais indicado para a avaliação do dano por choque térmico em refratários, uma vez que reproduz de forma mais significativa as condições de uso e melhor descreve a resistência do material à propagação das trincas formadas.

O método selecionado para a caracterização da resistência ao dano por choque térmico foi o de ciclos múltiplos, visando uma maior reprodução das condições de aplicação. Com a temperatura do forno mantida fixa em $1025^{\circ} \mathrm{C}$, os corpos de prova foram inseridos no forno e permaneceram por $15 \mathrm{~min}$. Após este intervalo de tempo, as amostras foram removidas, resfriando por $15 \mathrm{~min}$ em temperatura ambiente, caracterizando uma diferença de temperatura aproximada de $1000{ }^{\circ} \mathrm{C}$. Após o resfriamento, os corpos retornam ao forno, iniciando-se um novo ciclo.

As variações das propriedades mecânicas dos concretos, como módulo elástico e resistência mecânica, foram medidas visando-se a analise da degradação nas amostras causada pelos ciclos de choque térmico, uma vez que o surgimento de trincas decorrentes das tensões térmicas geradas altera estas propriedades.

O procedimento adotado para a avaliação da degradação do módulo elástico e da resistência mecânica em função dos ciclos de choque térmico seguiu a seguinte ordem: a) medida da resistência mecânica e do módulo elástico sem choque térmico; b) 10 ciclos de choque térmico por amostra, sendo que a cada 2 ciclos realizou-se a medida do módulo elástico; c) ao final de 10 ciclos, mediu-se a resistência mecânica das amostras. Desta forma, obteve-se o valor de módulo elástico para os ciclos $0,2,4,6,8$ e 10, e os valores da resistência mecânica sem choque térmico e após 10 ciclos.

O módulo elástico foi obtido pelo método de ressonância de barras, utilizando-se amostras na forma de barras de secção retangular e com dimensões próximas a $150 \mathrm{~mm} \mathrm{x}$ $25 \mathrm{~mm} \times 25 \mathrm{~mm}$. A partir das freqüências de ressonância obtidas e conhecendo a densidade do material, calcula-se o valor do módulo elástico $\mathrm{E}$, do módulo de cisalhamento $\mathrm{G}$ e do coeficiente de Poisson. Por ser um ensaio de natureza não destrutiva, é possível acompanhar a queda do módulo elástico de uma mesma amostra em função dos números de ciclos de choque térmico [10].

Devido à relação linear entre módulo elástico e resistência mecânica observada na Fig. 3, espera-se que o comportamento apresentado pelas curvas de módulo elástico em função do número de ciclos possa ser atribuído também à resistência mecânica.

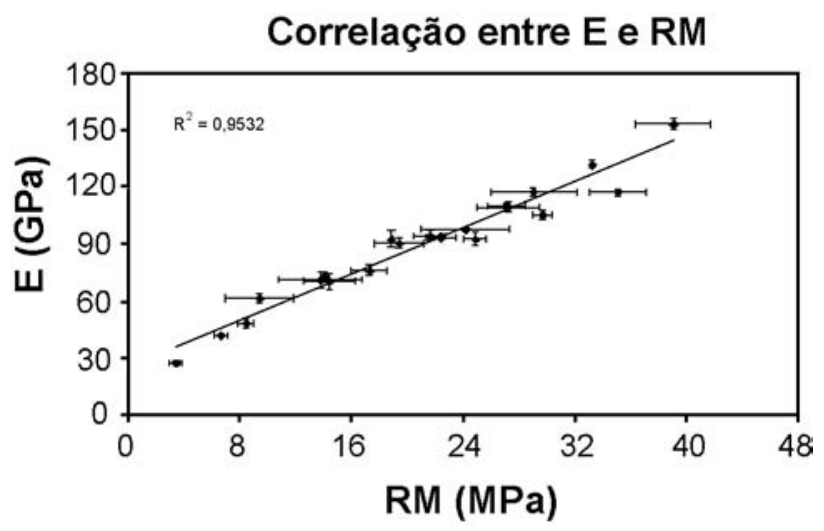

Figura 3: Correlação entre módulo elástico e resistência mecânica. [Figure 3: Correlation between elastic modulus and mechanical strength.]

As medidas de resistência mecânica foram realizadas por meio do ensaio de flexão 3 pontos (MTS Systems Corp., modelo 810, EUA) em corpos de prova na forma de barras (150 mm x $25 \mathrm{~mm} \times 25 \mathrm{~mm}$ ). A taxa de aplicação de carga foi de $24,9 \mathrm{~N} / \mathrm{s}$ e o módulo de ruptura foi obtido segundo a equação:

$$
\sigma_{\mathrm{f}}=\frac{3 \mathrm{PL}}{2 \mathrm{BH}^{2}}\left(\frac{\mathrm{L} / 2-\mathrm{X}}{\mathrm{L} / 2}\right)
$$


onde, P é a tensão aplicada no instante da fratura, L é a distancia entre os apoios, B é a largura, H é a altura da barra e X é o fator de correção e corresponde a distância entre a posição onde ocorreu a fratura e o centro da amostra.

\section{RESULTADOS E DISCUSSÃO}

O primeiro aspecto analisado foi o efeito do tipo de incorporação do espinélio no concreto, comparando-se o sistema alumina-espinélio (adição de espinélio pré-formado) e alumina-magnésia (espinelização in-situ). A Fig. 4 apresenta os resultados de VLD em função das temperaturas de queima, indicando a expansão residual das barras de concreto após a queima.

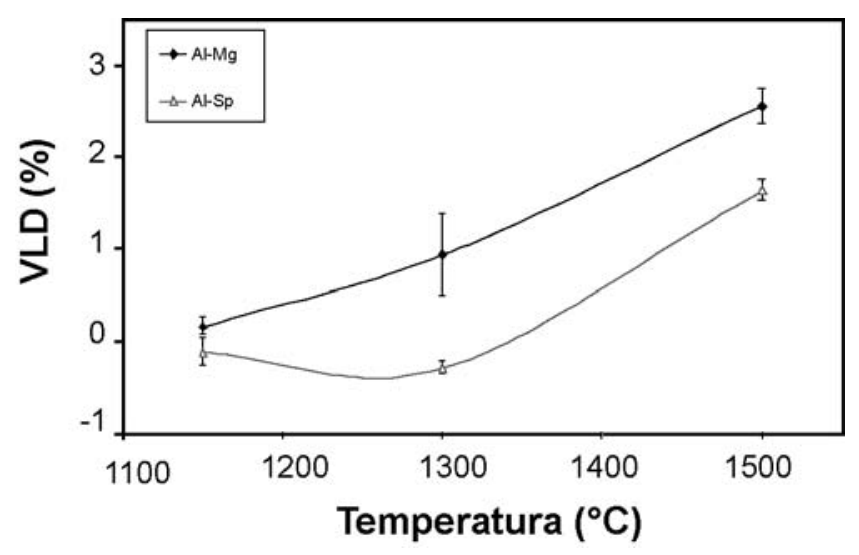

Figura 4: Expansão residual em função da temperatura de queima para concretos alumina-magnésia (Al-Mg) e alumina-espinélio (Al-Sp).

[Figure 4: Residual expansion as a function of firing temperature for different castables: alumina-magnesia (Al-Mg) and aluminaspinel (Al-Sp).]

$\mathrm{Na}$ faixa de temperatura de $1150{ }^{\circ} \mathrm{C}$ até $1300{ }^{\circ} \mathrm{C}$ a expansão dos concretos do sistema alumina-magnésia (Al$\mathrm{Mg}$ ) é superior a dos concretos do sistema alumina-espinélio (Al-Sp). Esta expansão está relacionada com a formação de
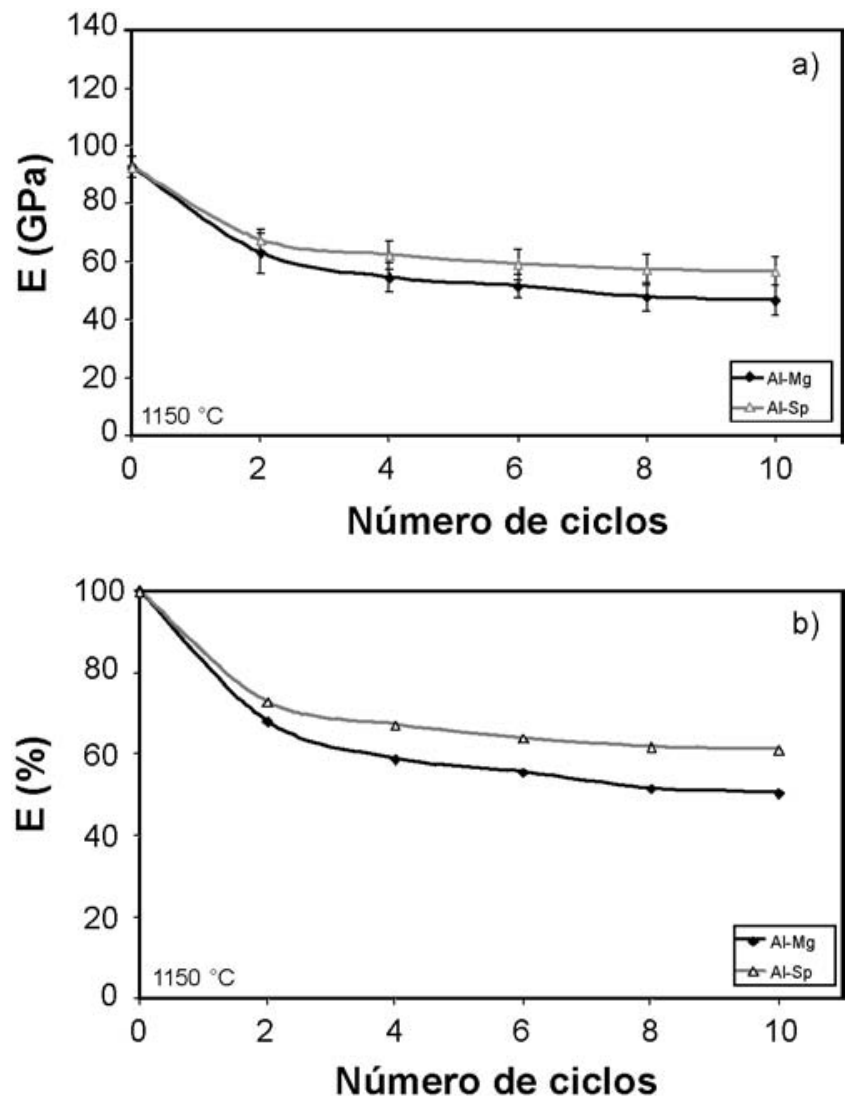

Figura 5: Degradação do módulo elástico em função do número de ciclos de choque térmico, em concretos queimados a $1150{ }^{\circ} \mathrm{C}$ : A) queda absoluta; B) queda percentual.

[Figure 5: Elastic modulus damage as a function of the thermal shock cycling for castables fired at $1150{ }^{\circ} \mathrm{C}$ : A) absolute loss; B) percentage loss.]

espinélio in-situ, já que nos concretos contendo espinélio pré-formado tal comportamento não é observado. Entre $1300^{\circ} \mathrm{C}$ e $1500{ }^{\circ} \mathrm{C}$, observa-se um comportamento expansivo acentuado dos dois tipos de concretos. Esta expansão está associada à formação do $\mathrm{CA}_{6}$, e pode ser favorecida pela presença de microssílica.

Tabela I - Relação entre porosidade aparente e resistência mecânica para concretos alumina-magnésia e alumina-espinélio. [Table I - Apparent porosity and mechanical strength relationship for alumina-magnesia and alumina-spinel castables.]

\begin{tabular}{cccccc}
\hline Composição & Microssílica & $\begin{array}{c}\text { Temperatura } \\
\text { de queima } \\
\left({ }^{\circ} \mathrm{C}\right)\end{array}$ & $\begin{array}{c}\text { Porosidade } \\
(\%)\end{array}$ & $\begin{array}{c}\text { Tensão de ruptura } \\
(\mathrm{MPa})\end{array}$ & $\begin{array}{c}\text { Módulo elástico } \\
(\mathrm{GPa})\end{array}$ \\
\hline Alumina- & \multirow{2}{*}{ Com } & 1150 & $15,0 \pm 2,9$ & $24,8 \pm 0,8$ & $92,7 \pm 3,7$ \\
Magnésia & 1300 & $17,7 \pm 2,8$ & $27,1 \pm 1,3$ & $110,2 \pm 1,5$ \\
(Al-Mg) & & 1500 & $22,8 \pm 2,7$ & $29,7 \pm 0,7$ & $105,3 \pm 2,6$ \\
\hline Alumina- & \multirow{2}{*}{ Com } & 1150 & $17,0 \pm 0,1$ & $19,4 \pm 1,3$ & $92,5 \pm 0,9$ \\
Espinélio & 1300 & $16,0 \pm 0,5$ & $29,5 \pm 2,1$ & $129,2 \pm 3,5$ \\
(Al-Sp) & & 1500 & $21,1 \pm 0,1$ & $24,9 \pm 2,2$ & $91,9 \pm 0,7$ \\
\hline
\end{tabular}


Além de resultar em maior expansão, a formação de fases in-situ contribuiu para o aumento da porosidade do concreto, como pode ser observado na Tabela I. Este fato está relacionado com a formação in-situ do espinélio e do $\mathrm{CA}_{6}$ em um ambiente sem constrição. $\mathrm{O}$ caráter expansivo destas fases tensiona a microestrutura do concreto e contribui para a formação de microtrincas, aumentando a porosidade.

As Figs. 5 a 7 representam a degradação sofrida do módulo elástico em função do número de ciclos de choque térmico, enquanto a Fig. 8 representa a resistência mecânica antes e após 10 ciclos de choque térmico, para três temperaturas de queima distintas: $1150{ }^{\circ} \mathrm{C}, 1300{ }^{\circ} \mathrm{C}$ e $1500{ }^{\circ} \mathrm{C}$. Todas as curvas de módulo elástico apresentaram comportamento semelhante, no qual a queda mais intensa ocorre nos primeiros ciclos, seguido pela estabilização dos valores após o quarto ciclo.

A $1150{ }^{\circ} \mathrm{C}$ o dano causado pelo choque térmico foi levemente superior para os concretos do sistema aluminamagnésia (Al-Mg), apresentando maior queda percentual de módulo elástico e menor valor de resistência mecânica após 10 ciclos de choque térmico, comparado com os concretos alumina-espinélio (Al-Sp). Ao se aumentar a temperatura de queima de $1150{ }^{\circ} \mathrm{C}$ para $1300{ }^{\circ} \mathrm{C}$, os concretos com
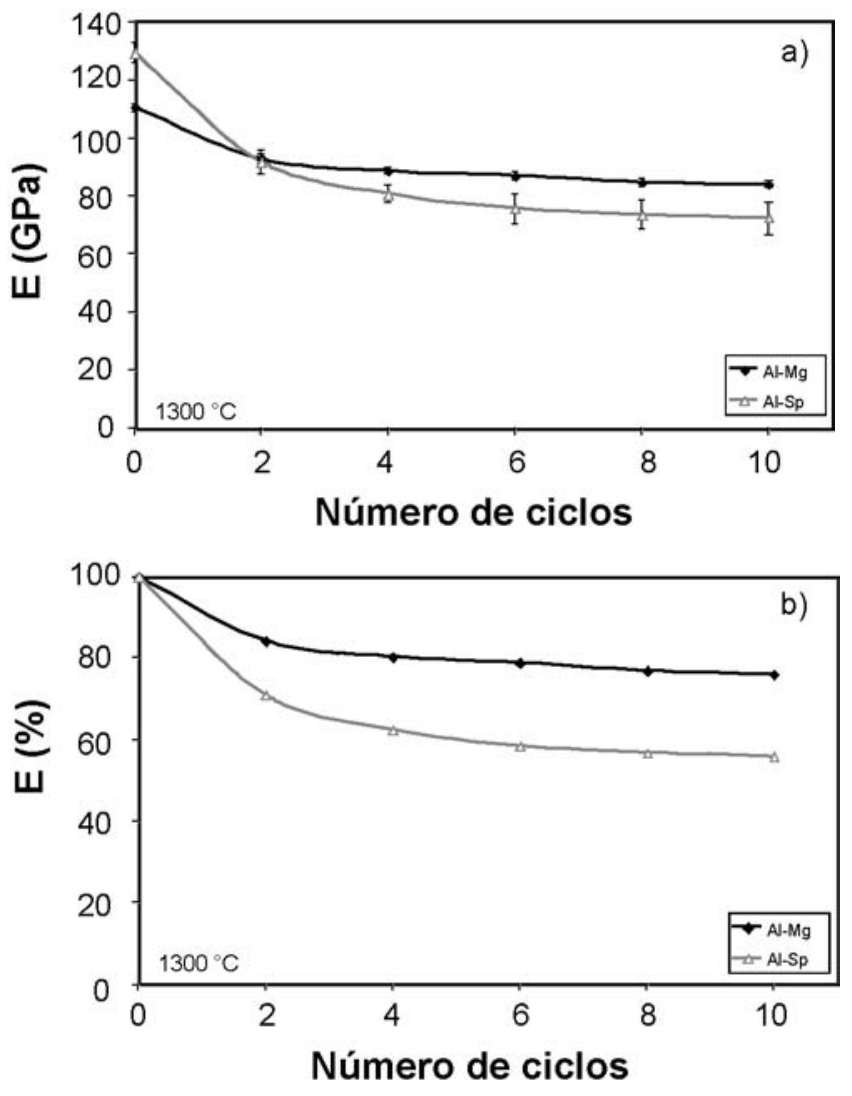

Figura 6: Degradação do módulo elástico em função do número de ciclos de choque térmico, em concretos queimados a $1300{ }^{\circ} \mathrm{C}$ : A) queda absoluta; B) queda percentual.

[Figure 6: Elastic modulus damage as a function of the thermal shock cycling for castables fired at $1300{ }^{\circ} \mathrm{C}$ : A) absolute loss; B) percentage loss.] espinelização in-situ melhoraram o desempenho, enquanto que a degradação nos concretos contendo espinélio préformado (Al-Sp) permaneceu praticamente inalterada. Sendo assim, a formação do espinélio in-situ possivelmente
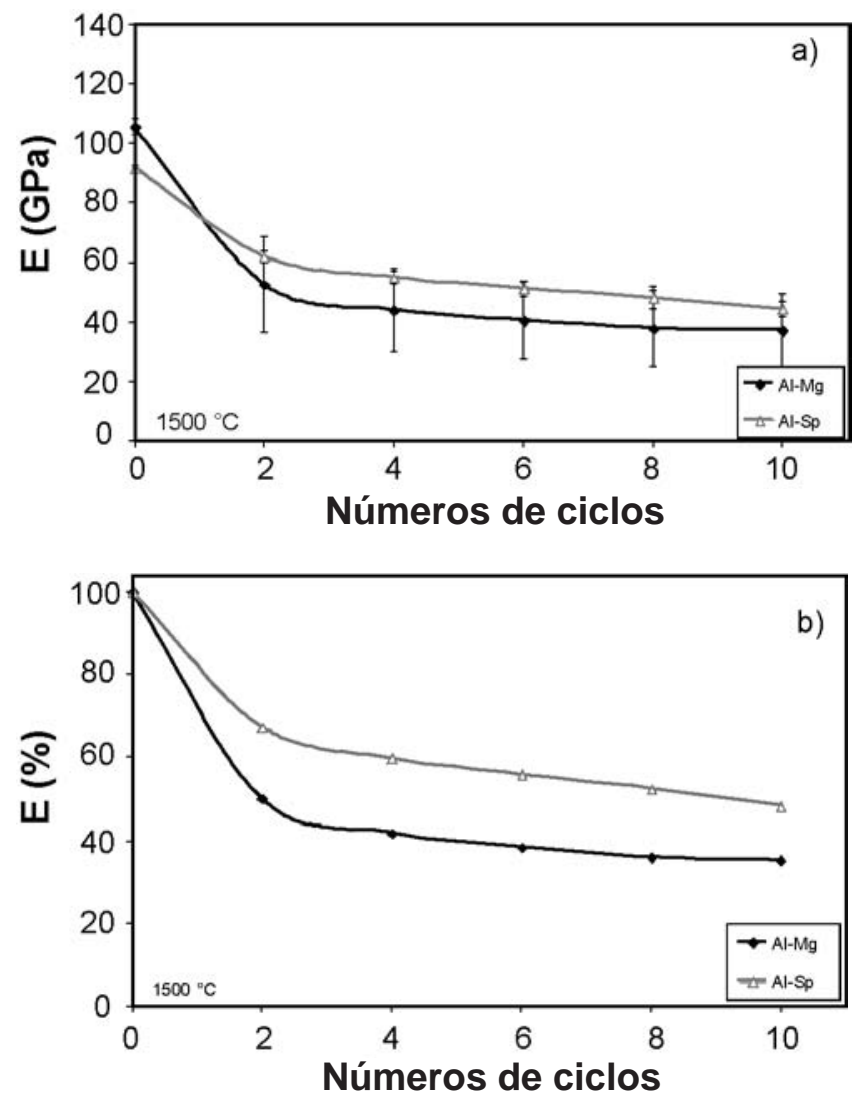

Figura 7: Degradação do módulo elástico em função do número de ciclos de choque térmico, em concretos queimados a $1500{ }^{\circ} \mathrm{C}$ : A) queda absoluta; B) queda percentual.

[Figure 7: Elastic modulus damage as a function of the thermal shock cycling for castables fired at $1500{ }^{\circ} \mathrm{C}$ : A) absolute loss; B) percentage loss.]

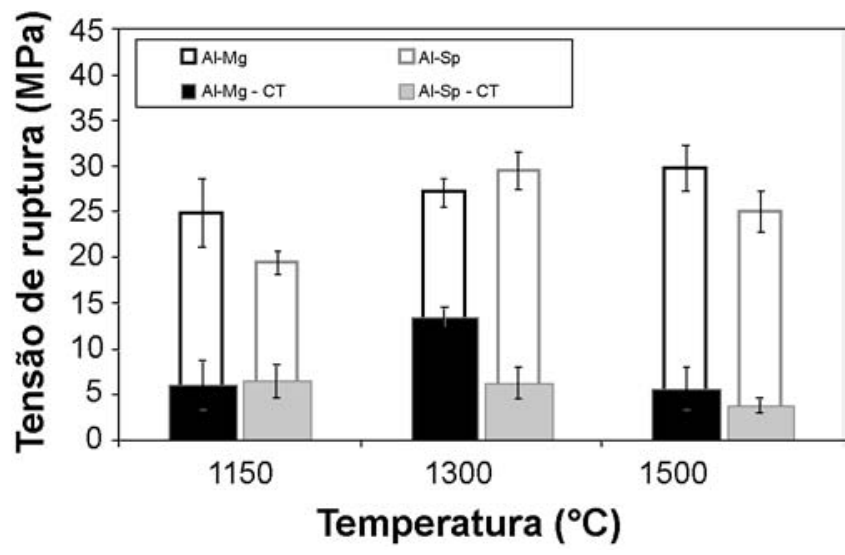

Figura 8: Medida da resistência mecânica antes (Al-Mg e Al-Sp) e após 10 ciclos de choque térmico (Al-Mg CT e Al-Sp CT).

[Figure 8: Mechanical strength before (Al-Mg and Al-Sp) and after 10 thermal shock cycles (Al-Mg CT and Al-Sp CT).] 
contribuiu para o aumento da resistência ao choque térmico por meio da formação de microtrincas e do aumento da porosidade aparente.

Elevando-se a temperatura de queima de $1300{ }^{\circ} \mathrm{C}$ para $1500{ }^{\circ} \mathrm{C}$, o desempenho dos dois tipos de concreto piora, sendo que a degradação dos concretos com espinelização insitu foi maior (representado na Fig. 7 pela queda percentual de módulo elástico a $1500{ }^{\circ} \mathrm{C}$ ). A princípio, poderia se concluir que na faixa de temperatura de uso das panelas siderúrgicas, os concretos com adição de espinélio préformado apresentam melhor desempenho frente ao choque térmico que os concretos alumina-magnésia. No entanto, este resultado pode ser distinto, caso o ensaio de choque térmico fosse realizado em concretos sob constrição.

Os concretos com espinelização in-situ apresentam maior expansão volumétrica durante a queima que os concretos com espinélio pré-formado. Em ambientes constritos, como no caso da panela de siderurgia, esta diferença de expansão pode favorecer a tenacificação do material com maior expansão, aumentando a resistência ao dano por choque térmico.

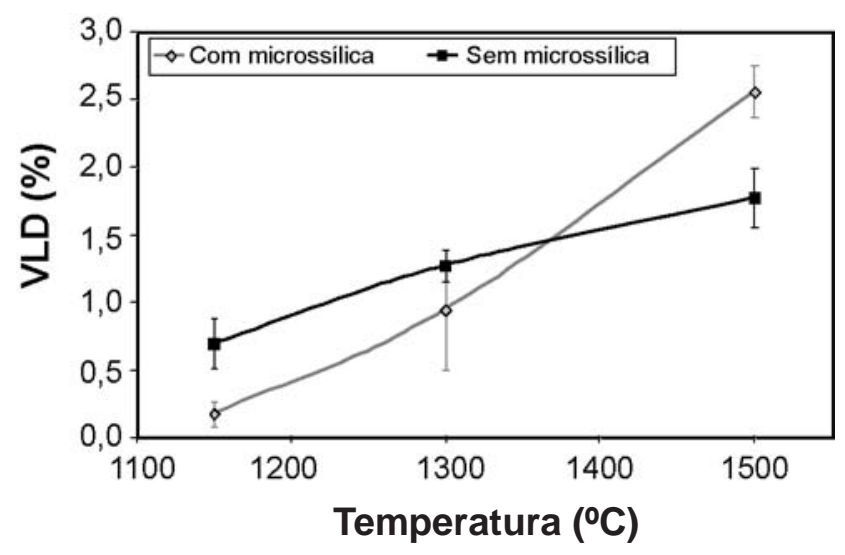

Figura 9: Expansão residual em função da temperatura de queima para concretos alumina-magnésia com e sem microssílica.

[Figure 9: Permanent linear expansion as a function of firing temperature for microssilica containing alumina-magnesia castables and alumina-magnesia castables with no microssilica.]
Outro aspecto avaliado foi o efeito da presença de microssílica. A Fig. 9 representa a expansão residual de dois concretos alumina-magnésia, com e sem microssílica.

Em temperaturas inferiores a $1300{ }^{\circ} \mathrm{C}$, a expansão foi maior nos concretos sem microssílica, porém, de $1300{ }^{\circ} \mathrm{C}$ para $1500{ }^{\circ} \mathrm{C}$, os concretos com microssílica apresentaram crescimento acentuado de VLD. Isto pode estar associado com o aumento da quantidade de $\mathrm{CA}_{6}$ formado na matriz, favorecido pela presença de microssílica. Assim como o espinélio, $\mathrm{o} \mathrm{CA}_{6}$ possui caráter expansivo durante a sua reação de formação, contribuindo para o aumento de VLD. Além disso, a microssílica acelera o processo de formação do $\mathrm{CA}_{6}$, gerando maior expansão. A formação in-situ afeta também a porosidade do concreto, uma vez que o $\mathrm{CA}_{6}$ contribui para o aumento da quantidade de microtrincas. Os efeitos da microssílica sobre a porosidade, a resistência mecânica e o módulo elástico estão representados na Tabela II.

As Figs. 10 e 11 representam a queda do módulo elástico em função dos ciclos de choque térmico, e a resistência mecânica sem choque térmico e após 10 ciclos, para concretos alumina-magnésia com e sem microssílica.

Os gráficos obtidos revelam que a presença de microssílica em concretos espinelizados queimados à 1500 ${ }^{\circ} \mathrm{C}$ reduz a resistência ao choque térmico dos materiais, uma vez que a degradação, medida pela queda percentual de módulo elástico e valor final de resistência mecânica após 10 ciclos, foi maior que nos concretos sem microssílica. Esta diferença de desempenho pode estar relacionada com a maior quantidade de fase vítrea presente nos concretos com microssílica. Outro fator que pode afetar a resistência ao choque térmico é o fato do tamanho dos poros dos concretos sem microssílica ser menor que dos concretos com microssílica [8]. Poros menores são mecanismos de tenacificação mais eficientes que poros grandes.

A presença de microssílica favorece a formação de fase líquida em temperaturas elevadas, possibilitando o aumento da resistência ao choque térmico por reduzir a tensão acumulada e deformar a ponta da trinca. No entanto, como o ensaio foi realizado até a temperatura ambiente, portanto bem abaixo da temperatura de transição vítrea. Desta forma, alterar a temperatura de

Tabela II - Relação entre porosidade e resistência mecânica para composições alumina-magnésia com e sem microssílica. [Table II - Porosity and mechanical strength relationship for alumina-magnesia castables with and without microssilica.]

\begin{tabular}{cccccc}
\hline Composição & Microssílica & $\begin{array}{c}\text { Temperatura } \\
\text { de queima } \\
\left({ }^{\circ} \mathrm{C}\right)\end{array}$ & $\begin{array}{c}\text { Porosidade } \\
(\%)\end{array}$ & $\begin{array}{c}\text { Tensão de ruptura } \\
(\mathrm{MPa})\end{array}$ & $\begin{array}{c}\text { Módulo elástico } \\
(\mathrm{GPa})\end{array}$ \\
\hline \multirow{2}{*}{$\begin{array}{c}\text { Alumina- } \\
\text { Magnésia }\end{array}$} & \multirow{2}{*}{ Com } & 1150 & $15,0 \pm 2,9$ & $24,8 \pm 0,8$ & $92,7 \pm 3,7$ \\
& & 1300 & $17,7 \pm 2,8$ & $27,1 \pm 1,3$ & $110,2 \pm 1,5$ \\
Alumina- & \multirow{2}{*}{ Sem } & 1500 & $22,8 \pm 2,7$ & $29,7 \pm 0,7$ & $105,3 \pm 2,6$ \\
Magnésia & & 1150 & $16,4 \pm 0,6$ & $14,4 \pm 1,9$ & $70,3 \pm 4,1$ \\
& & 1500 & $18,3 \pm 0,1$ & $17,3 \pm 1,3$ & $76,0 \pm 2,9$ \\
\hline
\end{tabular}



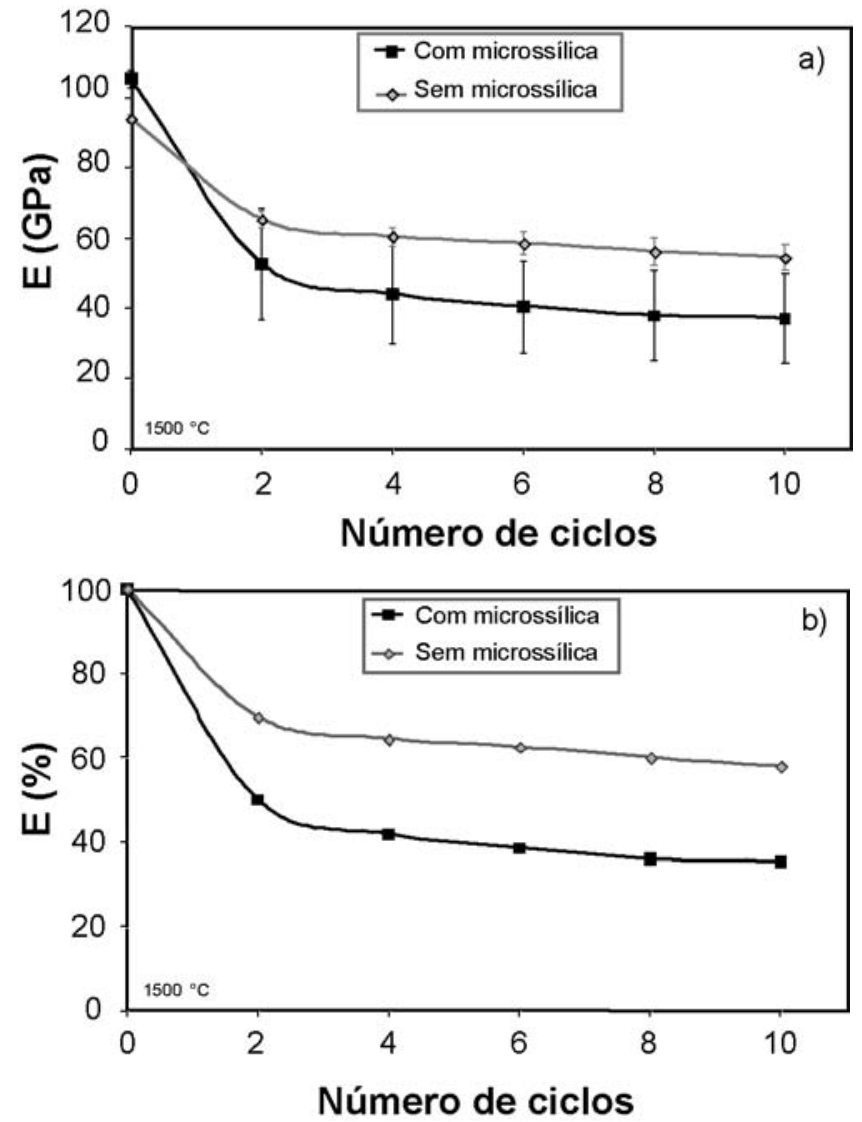

Figura 10: Degradação do módulo elástico em função do número de ciclos de choque térmico, em concretos queimados a $1500{ }^{\circ} \mathrm{C}$ : A) queda absoluta; B) queda percentual.

[Figure 10: Elastic modulus damage as a function of the thermal shock cycling for castables fired at $1500{ }^{\circ} \mathrm{C}$ : A) absolute loss; B) percentage loss.]

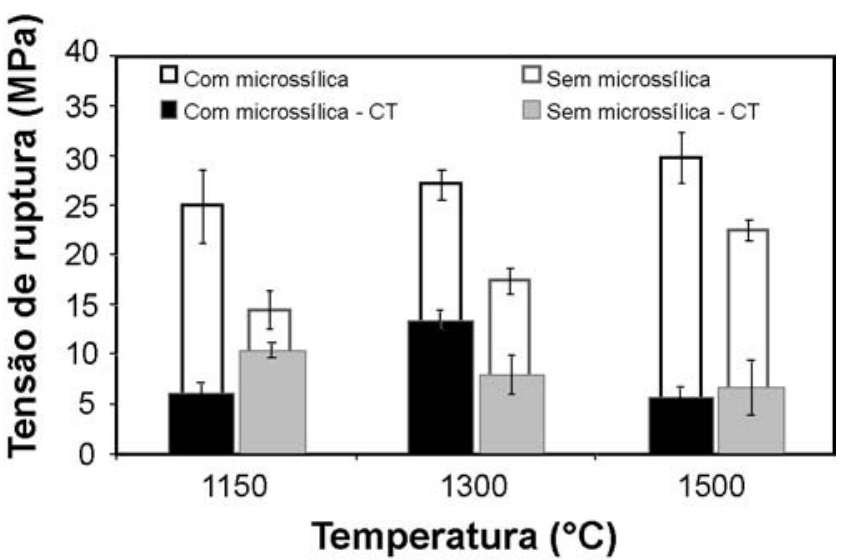

Figura 11: Medida da resistência mecânica antes e após 10 ciclos de choque térmico (CT).

[Figure 11: Mechanical strength before and after 10 thermal shock cycles.]

ensaio final de choque térmico $\left(>25^{\circ} \mathrm{C}\right)$ pode trazer uma análise mais completa da influência da microssílica e melhorar a compreensão do seu efeito na resistência ao choque térmico dos concretos.

\section{CONCLUSÕES}

O presente trabalho apresentou a importância de se caracterizar a resistência ao choque térmico dos concretos espinelizados usados no revestimento de panelas para refino secundário do aço. $\mathrm{O}$ desempenho de concretos aluminosos contendo espinélio frente ao choque térmico foi testado em laboratório, por meio da medida da variação do módulo elástico e da resistência mecânica. Foram analisados os efeitos do tipo de incorporação de espinélio e da presença de microssílica na resistência ao choque térmico dos concretos.

Foi observada uma relação direta entre a microestrutura dos concretos e a resistência à degradação por choque térmico. A formação de fases in-situ, como o espinélio e agulhas de $\mathrm{CA}_{6}$, pode ser controlada por meio da seleção adequada das matérias-primas, influenciando diretamente na microestrutura formada, e consequentemente, na resistência ao choque térmico.

O método de caracterização utilizado permitiu acompanhar a degradação das propriedades mecânicas em função do número de ciclos de choque térmico e mostrou que a maior degradação ocorre nos primeiros ciclos de choque térmico, tendendo posteriormente à estabilização. No entanto, o ensaio selecionado apresentou algumas limitações. Uma delas diz respeito à temperatura de ensaio. $O$ fato do ensaio ser realizado até temperatura ambiente elimina possíveis benefícios relativos à acomodação de tensões termomecânicas devido a presença de fase líquida. Adicionalmente, em temperaturas mais baixas, o material se torna mais frágil, algo mais evidente em concretos contendo microssílica devido a presença de fase vítrea, o que aumenta a degradação sofrida pelo corpo.

Por fim, um aspecto relevante foi a necessidade de avaliação do choque térmico sob constrição para concretos refratários alumina-magnésia, uma vez que seu caráter expansivo com a formação de espinélio e $\mathrm{CA}_{6}$ pode tenacificar o material, diminuindo assim a sua degradação por choque térmico. Tal procedimento tem sido alvo de pesquisa dos autores do presente trabalho.

\section{AGRADECIMENTOS}

Ao suporte financeiro e técnico fornecido por CNPq, FAPESP e Magnesita S.A.. À contribuição dada por Douglas H. Milanez, Eric Y. Sako e Felipe R. Semeghin.

\section{REFERÊNCIAS}

[1] M. Fuhrer, A. Hey, W. E. Lee, J. Eur. Ceram. Soc. 18 (1998) 813.

[2] W. E. Lee, R. E. Moore, J. Am. Ceram. Soc. 81, 6 (1998) 1385.

[3] S. Mukhopadhyay, P. K. Das Poddar, Ceram. Int. 30 (2004) 369.

[4] F. Simonin, C. Olagnon, S. Maximilien, G. Fantozzi, J. Am. Ceram. Soc. 83, 10 (2000) 2481. 
[5] M. A. Quintela, F. D. Santos, C. A. Pessoa, J. A. Rodrigues, V. C. Pandolfelli, Proc. Unified Int. Tech. Conf. Refractories, Orlando, EUA (2005) 380.

[6] D. P. Hasselman, J. Am. Ceram. Soc. 52, 11 (1969) 600.

[7] J. Homeny, R. C. Bradt, Thermal stresses in materials and structures in severe thermal environments (1980) 343.
[8] S. K. Chen, M. Y. Cheng, S. J. Lin, Y. C. Ko, Ceram. Int. 28 (2002) 811.

[9] J. Homeny, R. C. Bradt, Am. Ceram. Soc. Bull. 63, 8 (1984) 1016.

[10] Norma ASTM, C-1198.

(Rec. 12/09/2007, Ac. 27/12/2007) 